\title{
Papers
}

\section{Handset-based measurement of smartphone service evolution in Finland}

Received (in revised form): 22nd November, 2007

\begin{abstract}
Hannu T. Verkasalo
works as a research scientist at Helsinki University of Technology, Finland. Verkasalo has published several conference and journal papers on the evolution of mobile service market, and currently he is pursuing a doctoral dissertation on the emergence of the mobile internet. Verkasalo has particularly focused on empirical mobile service research utilising the recently developed handset-based research method. In addition to research work, Hannu Verkasalo gives lectures on network economics, operator business and telecommunication regulation. Verkasalo has also closely collaborated with Nokia in mobile end-user research. Verkasalo holds a Lic.Sc. (Technology) degree from Helsinki University of Technology, an MSc (Business Administration) degree from Helsinki School of Economics and an M.Soc.Sc. (Statistics) degree from the University of Helsinki.
\end{abstract}

\section{Keywords mobile services, handset-based end-user research, Finnish mobile market}

\begin{abstract}
This paper carried out an extensive empirical study on mobile service usage in Finland. A newly developed handset-based mobile service research platform was utilised with automatic data mining procedures. The approach provided a scalable and novel market research approach. A typical Finnish panelist spends a daily average of $33 \mathrm{~min}$ with a smartphone. Most of this time is allocated on voice calls (33 per cent) and messaging ( 24 per cent), the overall communication usage representing 60 per cent of all usage time. Younger people and men are still the most active users of smartphones. The Finnish market has developed particularly in the use of packet data and person-toperson services. Handset bundling has indirectly driven usage because more data, voice and SMS packet plans are available. Handset bundling is also reflected in the increased use of operatorspecific clients. ABPU (average billing per user) levels correlate with data, voice and SMS service usage, whereas no clear correlation between ABPU and (free) offline service usage exists. People still consider the pricing and technical implementation of the mobile WWW and email as bottlenecks for wider mobile internet usage. WLAN traffic already represents a significant share of aggregated traffic volume, although the number of WLAN-capable phones in the panel is small. Mobile data volume is evolving gradually towards multimedia and infotainment from mere static content and communication. Three distinctive end-user segments were identified when demonstrating usage-based clustering of users. The handset-based research approach has many advantages to alternative market research tools. Journal of Targeting, Measurement and Analysis for Marketing (2007) 16, 7-25. doi:10.1057/palgrave.jt.5750060; published online 7 January 2008
\end{abstract}

\section{INTRODUCTION}

Service is generally considered as a nonmaterial equivalent of a good. According to Kotler and Armstrong, ${ }^{1}$ services are 'activities or benefits

Correspondence: Hannu T. Verkasalo, Research Scientist,

Networking Laboratory, Helsinki University of Technology, P.O. Box 3000, TKK FI-02015, Finland.

Tel: +358 405959663 ;

Fax: + 35894512474 ;

E-mail: hannu.verkasalo@tkk.fi offered for sale that are essentially intangible and do not result in the ownership of anything'. Electronic services are services that involve electronic transactions. A mobile service, further, is defined in this paper essentially as a service that is consumed by the end-user with a mobile handset. Mobile devices integrate electronic services to the user's context (see eg Ojala et al. ${ }^{2}$ and Abowd et al. $^{3}$ ) and provide the possibility for the development of ubiquitous electronic services. 
Mobile devices have facilitated the innovation of new kinds of services and have created a whole new industry. This paper sets out to provide novel empirical insights on the adoption and usage of new mobile services in Finland in 2005-2006 with a new handset-based research approach.

Mobile services are facing many potentially disruptive impacts (for disruptive evolution, see Christensen ${ }^{4}$ ). On the one hand, new smartphone devices support a wider portfolio of services to be provided to end-users, thus driving increasing saturation both in the service and the subscriber markets. ${ }^{5}$ Maslow ${ }^{6}$ suggested that there are different layers of needs. Similarly, it can be argued that there are different layers of needs with regard to mobile services, and some of the new services fulfil different kinds of needs than the first mobile communication services (eg entertainment and creativity vs communications and belongingness). On the other hand, new technologies (such as internet packet data access and challenger radio access technologies) drive new service innovations and increase the end-user freedom of choice. The special characteristics of mobile services (see eg Heinonen and Pura ${ }^{7}$ and Clarke and Flaherty ${ }^{8}$ ) and the potential business aspects involving changes in mobile ecosystem structures ${ }^{9}$ emphasise the importance of empirical mobile service research.

This research paper presents some of the most important findings from a recent Finnish smartphone study arranged in fall 2006. The study relies on a novel handset-based end-user research method. The research problem is 'how to utilize handset-based end-user data collection in crosssectional and longitudinal mobile market studies?' The developed research platform supports handset-based observations of end-user behaviour and service usage. This paper sets out to study the high-end of the mobile market (ie early adopters; see eg Rogers ${ }^{10}$ ), consequently providing early insights on mobile service usage trends that might cross the chasm ${ }^{11}$ later in the diffusion cycle. The Finnish smartphone study was first conducted in 2005, and longitudinal comparisons are therefore presented between 2005 and 2006. A new approach of carrying out end-user segmentation based on usage (instead of demographic) data is presented, too. At the end of the paper, a discussion is presented on the findings of the paper and their relation to other published studies.

\section{HANDSET-BASED END-USER RESEARCH}

Many research tools are available for empirical mobile end-user studies. All the available methods have their own advantages and shortcomings. See Appendix B for a comparison of alternative research methods.

Surveys $^{12}$ are a typical way of conducting end-user research. A survey is a wide concept including questionnaires, interviews and laboratory-oriented research settings.

Questionnaires are scalable, but offer little flexibility or accuracy. On the other hand, typical problems of interviews include subjectivity and poor scalability. The interpretations of both questions and answers pose challenges in both questionnaires and interviews. ${ }^{13}$ Laboratory tests refer to specific preplanned tests taking place in a fixed context (such as in a laboratory). These tests are typically quite extensive, flexible and accurate, but are expensive and do not provide observations from real-life situations.

The research methods discussed above provide few possibilities for automated data mining. With new research platforms, the automation of data mining procedures can easily be implemented. For example, traffic measurements take place in the network, and this is one possible way to study, for example data service usage. Examples from the academic community include eg Peuhkuri, ${ }^{14}$ Viipuri ${ }^{15}$ and Kivi. ${ }^{16}$ Network server side logs or other databases provide another way to study service usage, and typically the nature of data is standardised to facilitate automatic data mining. Examples of the utilisation of server-originated data include, for example Kamvar and Baluja ${ }^{17}$ and Opera. ${ }^{18}$ Charging or other customer databases are also an alternative source of data, although an access to this kind of data is difficult to arrange. Also, the analysis of charging records can be automated quite well (see eg Wei and Chiu ${ }^{19}$ ).

The major challenges in the above-mentioned methods include the lack of accurate user-level data and the limitations due to the subjective 
nature of many research methods (eg questionnaires and interviews). For these challenges, a handset-based research platform has been developed. ${ }^{20}$ The platform supports very accurate end-user studies in the mobile domain. Data acquisition and data mining procedures are centralised. A handset-based client is logging data points related to end-user behaviour, then sending them to centralised servers, after which automated data analysis procedures are adopted in data mining. Panel studies consisting of several hundred smartphone customers are typically arranged. The research method was introduced in Verkasalo and Hämmäinen. ${ }^{20}$ Some exemplary results from the research already published includeVerkasalo, ${ }^{21}$ Verkasalo and Hämmäinen, ${ }^{22}$ Hämmäinen et al., ${ }^{23}$ Verkasalo ${ }^{24,25}$ and Verkasalo. ${ }^{9}$ In addition to accurate usage-level data on service usage, the research platform provides a possibility to tackle end-user experience through various questionnaires. Efficient automation of data analysis can be built on the platform because of the data's standardised nature.

\section{DATA SET}

SMS recruitment messages were sent to 28,000

Finnish consumer subscribers who owned a Nokia S60 device. A total of 1,071 customers visited the recruitment site and answered to the beginning questionnaire. This corresponds to a satisfactory pull-rate of 3.8 per cent. Out of these 1,071 registered panelists, only 695 (65 per cent) managed to generate at least three active weeks of smartphone usage. The rest either did not manage to install the research client or then quit the panel study earlier than was supposed. Some people might also have used their smartphones with the research client as a secondary phone. Out of these 695 active panelists, 395 (57 per cent) were willing and answered mobile pop-up questionnaires. These questions are asked with the help of pop-up windows during the panel study at specific moments or contexts. Out of the 695 active panelists, 548 (79 per cent) answered the final questionnaire, which was more comprehensive than the beginning questionnaire. In addition to demographics, the questionnaires covered various background questions related to user motivation, usage patterns and opinions on the usability and performance of mobile services.

Seventy-eight per cent of active panelists were male, and 18 per cent were female. Four per cent of the active panelists did not answer the gender question. Most panelists (66 per cent) were 20-39 years old. Only 29 teenagers participated in the panel, and there were 28 panelists who were older than 60 years. Eighty-six per cent of panelists paid the bill themselves, and 63 per cent were working full-time. Seventeen per cent of panelists were students, and 6 per cent were unemployed people. Forty-seven per cent of subscriptions were post-paid and bundled with the handset. Forty-four per cent were post-paid, but the handset was not included (unbundled). Nine per cent of panelists did not know or did not want to answer the question relating to their type of subscription.

Usage-based pricing has a fixed cost per amount of usage. Block-pricing in this study includes data packages up to $100 \mathrm{MB} /$ month, SMS plans up to 1,000 messages/month and voice plans up to $1,000 \mathrm{~min} / \mathrm{month}$. Flat-rate plans consist of plans that exceed these upper limits of block-pricing categories or are truly flat-rate (no upper limits for usage). Usage-based pricing is still the dominant pricing scheme in Finland. In voice, SMS and data the usage-based pricing plans represented 52, 65 and 64 per cent of all plans, respectively. Forty-five per cent of voice subscriptions were block-priced and 4 per cent were flat-rate. Thirty per cent of SMS subscriptions were block-priced and 5 per cent were flat-rate. Thirty-two per cent of data subscriptions were block-priced and 5 per cent were flat-rate.

The panel consisted of early-adopter customers, as in earlier handset-based service studies (see eg Verkasalo $^{21}$ ). These people are likely to be more active in exploring new services. These kinds of panelists have probably both the intention and the capability to use new mobile services. Thirty-seven per cent of panelists considered themselves either experienced or very experienced smartphone users, whereas only 19 per cent considered themselves as beginners. 
Forty-seven per cent of panelists claimed that they are normal people. A typical panelist had an ABPU (average billing per user) of $€ 40 /$ month (on average, the Finnish ABPU is about $€ 25 /$ month $^{26}$ ). Sixteen per cent of panelists had an ABPU level higher than $€ 60 /$ month.

Out of all handsets $3 \mathrm{G}$ devices represented 71 per cent. In 2005, in a similar study, the share of $3 \mathrm{G}$ handsets was only 20 per cent. Out of all devices 4 per cent were WLAN-capable. The handset bundling has positively contributed to the adoption of $3 \mathrm{G}$ handsets. This directly affects the handset replacement rate, which has been quite poor earlier in Finland. ${ }^{27}$ Most people actively used their smartphones in the panel for at least two months. A typical (median) customer had 67 active usage days of smartphone usage.

In general, the panelists included in this study are more technologically oriented people than the mass market. Forty-three per cent of panelists said that they regularly use nonperson-to-personoriented applications with their smartphone, and 32 per cent said that they use these applications occasionally. Only 25 per cent said that they do not use these new features too much, indicating that they prefer smartphones as conventional communication devices. When asked from the panelists, it became obvious that particularly WEB/WAP browsing, MMS and offline multimedia playback are the new advanced features that people are looking forward to.

\section{GENERAL SMARTPHONE USAGE}

Voice and SMS are still the most popular smartphone services. These services experience usage penetration rates of 100 per cent (everybody use them), and median usage frequencies of 80-90 per cent (meaning that people use them basically every day). Camera, productivity applications, browsing, MMS and offline multimedia usage have attracted decent masses (penetration more than 60 per cent), too, although median usage frequencies are only 10-15 per cent (meaning that these services are used on average once a week). These results indicate that people are truly interested in at least exploring new services, and 90 per cent of panelists said they would like to see similar functions in their smartphones as in today's computers. Seventy-four per cent of panelists said that they enjoy exploring new smartphone services.

Fifty-seven per cent of panelists have tried games, and infotainment applications (operator clients, news portals, content access clients) achieve usage penetration of 39 per cent. Eight per cent of panelists have tried dedicated thirdparty email clients, and 39, 43 and 59 per cent have explored dedicated imaging/image editing, movie playback and music playback applications, respectively. Twenty-four per cent have tried some navigation applications. In terms of cumulative activations in the panel, PIM (personal information management, including applications such as Contacts, Log and Calendar) and messaging are the most used application categories (Figure 1).

A typical Finnish panelist allocates 33 per cent of her usage time on voice calls, and 24 per cent on messaging. Including additionally PIM applications (mostly relating to initiation of voice calls or SMS messages), about 60 per cent of usage time is related to communications. In 2005, this same figure was 70 per cent, and therefore steps have been taken towards more advanced applications. A typical panelist spends about $10 \mathrm{~min} /$ day on voice calls and $7 \mathrm{~min}$ on messaging, but there are clearly more active users, too. The top 25 per cent of messaging users, for example, spend an average of 12-26 min on messaging, and the top 25 per cent of voice users spend an average of $15-30 \mathrm{~min} /$ day on voice. A typical panelist allocates 5 per cent of her time on browsing, 4 per cent on games and 12 per cent on multimedia. The share of time spent with multimedia applications is increasing. A typical panelist spends $33 \mathrm{~min} /$ day in using smartphone, and 20 per cent of panelists spend more than $60 \mathrm{~min} /$ day with smartphone. A typical office worker, in comparison, spends $280 \mathrm{~min} / \mathrm{day}^{28}$ using computer. A typical television watcher spends, in comparison, almost $180 \mathrm{~min}^{29}$ with television every day.

A typical male teenager uses smartphone $61 \mathrm{~min} /$ day, whereas a female teenager spends only $36 \mathrm{~min}$. In older age categories, the 
Time Allocation in 2005

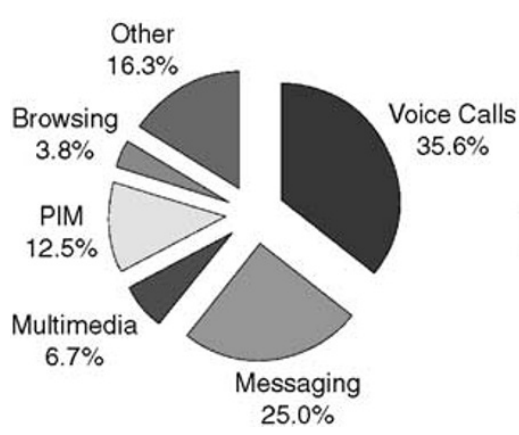

Time Allocation in 2006

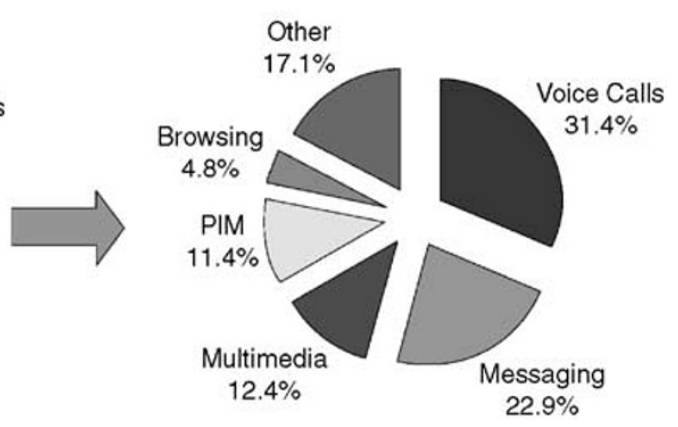

Figure 1: A typical user's daily time allocation on mobile services 2005 and 2006

differences between men and women are small. However, the older the panelist, the less time/day she uses with smartphone. The panelists of the largest age category (20-29 years) spend about 36-37 min/day with smartphone, whereas 60-60year-old panelists only spend $19 \mathrm{~min} /$ day (a difference of 50 per cent).

Eight per cent of all application activations are from the third-party domain. Third-party applications are applications that are not integrated in the S60 software platform. These applications might be preinstalled by Nokia, operators or service providers, or then they are installed by the user herself as add-on applications. In 2005 the share of third-party activations was 7 per cent.

Forty-four per cent of panelists have installed applications to the handset during the panel, and 87 per cent of panelists say that they have installed applications either before or during the panel (data is from questionnaires). Those panelists who installed applications during the panel on average installed on average one application/ month. A typical user only installed 1-2 applications during the whole panel period. Six per cent of all panelists install at least four applications/month. Men and younger people are more inclined to install applications.

Seventy per cent of male teenagers have installed applications, whereas only 54 and 49 per cent of $20-29$ or 30-39-year-old men have done the same, respectively. In general, only about 20-25 per cent of women have installed applications (Figure 2).

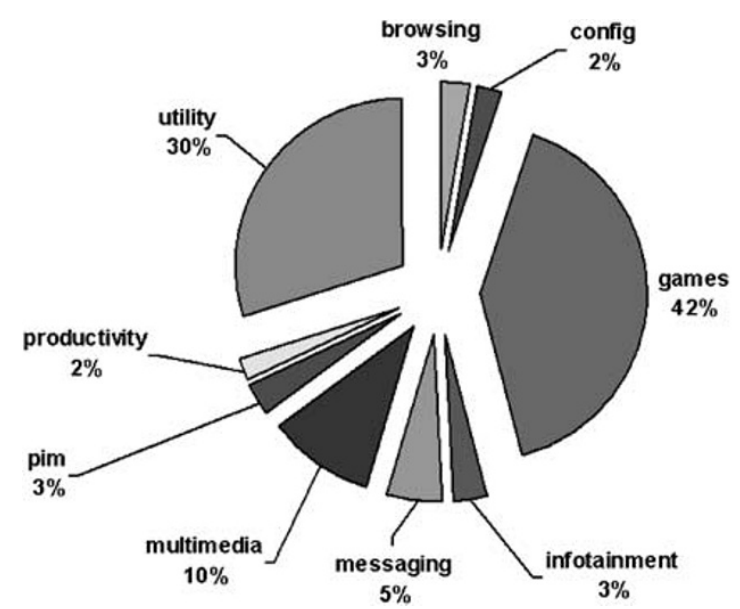

Figure 2: Distribution of application installations

Installed applications are mostly games (42 per cent), utility applications (eg navigation clients, small utility applications like AutoLock, virus scanners; 30 per cent) and multimedia applications (10 per cent). All in all, 1,628 application installations were observed in the panel, and 765 different installed applications were identified. Eighteen per cent of panelists have installed games, 15 per cent have installed utility applications, 10 per cent have installed multimedia applications and 6 per cent have installed messaging clients. Sixty per cent of panelists say that they consider the possibility of installing applications either important or very important, and 36 per cent say that application installations are a good feature. Therefore, almost all panelists have a positive attitude to add-on applications. 
Fifty-six per cent of all installed Java applications were removed already during the panel, but only 39 per cent of native Symbian applications were removed. Java applications are of such type (mostly games) that they do not 'survive' in the handset long. About 50 per cent of all applications installed during the panel are also removed during the panel. Productivity, browsing and configuration applications survive the longest (all these application categories relate to utilitarian benefits rather than hedonic benefits). Add-on applications experience similar usage than normal computer applications. In other words, people experiment with new applications for a while, but if they are not satisfied or if they simply do not need them, they remove the application quite soon. Possible reasons for removing the application include:

- disappointing performance;

- price (for continuing usage/registering);

- limited trial period;

- poor usability;

- getting bored with the application;

- new substitute applications emerge;

- new version has come up;

- limited memory capacity in the handset.

If the installed application is removed during the panel, this typically happened already during the same day as the application was installed.

Therefore, people quickly take a glance at the application and then decide whether it is worth keeping in the handset or not. People prefer installing applications with PC Suite (through computer) or from memory card, as only 17 per cent of application installations are initiated through a message push link and 11 per cent are downloaded with the browser and then installed to the handset.

\section{PERSON-TO-PERSON SERVICES}

All panelists have used voice and SMS. Only two panelists have tried push-to-talk, and three panelists have tried VoIP calls. Fourteen per cent have tried video calls, although observed usage is very infrequent. Perhaps people have merely explored how these services work. Fifty-three per cent of panelists have sent an MMS message and 59 per cent of panelists have received one. About 12 per cent of panelists have tried mobile email with the S60 native messaging client, but some people have additionally used third-party email solutions or webmail. All in all, 21 per cent of panelists have used mobile email. Instant messaging is used (through third-party clients) by 5 per cent of panelists. Bluetooth messaging service (to other phones) is explored by a third of the panelists.

A typical panelist places and receives 12 voice calls/week, the number of weekly calls totalling 24. Clearly, those who have flat-rate or blockpriced voice plans place more voice calls than those who face usage-based voice pricing. The difference between flat-rate and block-priced plans is 14 per cent (in terms of median intensities) and between block-priced plans and usage-based subscriptions, it is 28 per cent. Accidental calls are excluded from these studies. Forty per cent of panelists place more than two voice calls a day. A typical voice call lasts only $1.3 \mathrm{~min}$, and only 15 per cent of voice calls are longer than $5 \mathrm{~min}$. Panelists mostly (60 per cent) start the voice call from log application, Contacts/ Phonebook being the second most popular initiating application (35 per cent of all voice call actions). Sixty per cent of outbound voice calls go to the top-5 favourite contacts, and a typical panelist has called 34 different numbers during the panel, contacting typically eight different voice contacts every week. A typical panelist has 116 contact entries in the phonebook (Table 1).

About 90 per cent of all panelists use SMS every week, and everybody has at least once tried SMS during the panel. About 25 per cent of all panelists send at least two SMS messages a day. About 13 per cent of all panelists have sent SMS messages every single day, although those panelists who have a flat-rate SMS plan use SMS even more frequently. Thirty-three per cent of panelists with a flat-rate SMS plan have sent SMS messages every day. As in voice calls, in SMS people with flat-rate subscriptions both send and receive more messages than people with smaller block plans or completely usage-based pricing. Panelists with flat-rate, block-priced and usage-based plans on 
Table 1: Mean voice usage intensity [Minutes/Month/User]

\begin{tabular}{lllrc}
\hline & $\begin{array}{l}\text { Usage- } \\
\text { based }\end{array}$ & $\begin{array}{l}\text { Block- } \\
\text { priced }\end{array}$ & Flat-rate & Total \\
\hline Very low ABPU & 257 & 288 & 151 & 263 \\
Low ABPU & 283 & 336 & 210 & 311 \\
High ABPU & 357 & 361 & 631 & 384 \\
Very high ABPU & 384 & 505 & 1,475 & 542 \\
Total & 296 & 397 & 983 & 384 \\
\hline
\end{tabular}

Table 2: Mean outbound SMS usage intensity [Messages/ Month/User]

\begin{tabular}{llccc}
\hline & $\begin{array}{l}\text { Usage- } \\
\text { based }\end{array}$ & $\begin{array}{l}\text { Block- } \\
\text { priced }\end{array}$ & Flat-rate & Total \\
\hline Very low ABPU & 38 & 41 & 135 & 45 \\
Low ABPU & 42 & 59 & 159 & 47 \\
High ABPU & 38 & 58 & 229 & 55 \\
Very high ABPU & 67 & 100 & 190 & 97 \\
Total & 45 & 72 & 183 & 63 \\
\hline
\end{tabular}

average send 24, 11 and 5 SMS messages a week, respectively (these are medians; Table 2 projects mean numbers).

Generally, people receive almost double the number of sent messages, this is probably due to operator-originated or automatic service messages. A typical SMS message is 64 characters long, and at 160-170 characters there is a clear peak because many people optimise the message length by just filling in one full SMS message. Eight per cent of all outbound SMS messages consume at least two standard SMS messages. A typical panelist writes ca. 28 characters/min when writing SMS messages, and this just equals the average SMS writing speed measured in another study. ${ }^{30}$ Active SMS users not only write significantly faster than passive users, but they also write longer messages on average. Seventy-seven per cent of all outbound SMS messages go to the top-5 favourite contacts. Therefore, SMS contact networks are more concentrated than voice contact networks. This most likely results from the fact that fixed-line telephones cannot receive SMS messages, and SMS messages are typically not used in business use. A typical panelist has sent SMS messages to 15 different numbers during the panel, on average contacting three different contacts per week with SMS. In MMS almost all messages go to the top- 5 favourite contacts, because only advanced phones can receive MMS messages. On the other hand, MMS messages are even more personal (free-time oriented) than SMS messages.

Almost all (95 per cent) SMS messages are sent via the S60 native messaging client or the specialised S60 SMS messaging shortcut. In MMS messages, however, Gallery application (47 per cent) is the most dominant method to send messages, followed by the S60 native messaging client (33 per cent) and Camera (15 per cent). Therefore, people are capable of utilising the messaging shortcuts embedded in Nokia S60 multimedia applications.

Ninety-nine per cent of received MMS and SMS messages are read before the panel end. Ninety-one per cent (MMS) and 90 per cent (SMS) of messages are read within one hour from receiving the message. Fifty per cent of received MMS messages and 68 per cent of received SMS messages are removed before the panel end, but only 11 per cent (MMS) and 23 per cent (SMS) are removed within one hour from reading the message. People respond to incoming messages quite actively. Thirty-seven per cent of inbound SMS messages are responded with a reply message, and 24 per cent of received MMS messages are replied to. In addition, 48 per cent of all outbound SMS messages are replies, whereas only 14 per cent of outbound MMS messages are replies. Therefore, SMS is quite a chat-oriented service after all. Forwarding SMS or MMS messages is not common, as only 5 per cent of outbound SMS messages are forwards and 1 per cent of outbound MMS messages are forwards. People typically reply to SMS messages within $1.3 \mathrm{~min}$ from reading, and they typically forward inbound message within $0.1 \mathrm{~min}$. Typically, people read received SMS messages within $0.4 \mathrm{~min}$ from receiving.

Email, MMS, instant messaging, push-to-talk, video call and Bluetooth services experience only occasional usage and they cannot be compared to SMS or voice. Those who have data plans are more likely to explore mobile email and other packet data-oriented person-to-person services. In the future, the emergence of mobile VoIP and all the 
other challenger services one should keep an eye on. Currently they are explored by only a handful of these early-adopter customers (Figure 3).

MMS messages mostly consist of photos and text. Forty-three per cent of all outbound MMS messages consist of a JPG photo and a text part, and 31 per cent of all outbound MMS messages include only one JPG photo (without text). Four per cent of outbound MMS messages consist of only text, and these are probably reply MMS messages in which people did not include any multimedia. In outbound email attachments photos (93 per cent) dominate even more, but in inbound email attachments more variance can be observed. Roughly 40 per cent of inbound email attachments are office documents or something else (not related to photos). Similarly in outbound Bluetooth attachments photos dominate, but in inbound messages only 38 per cent are photos, 26 per cent are music tracks and 21 per cent are applications. Clearly people use Bluetooth in exchanging music and applications with a laptop or a desktop computer. Based on the mobile questionnaire, music is the second most important content type people transmit via Bluetooth, photos and images being the most popular category according to the users themselves. Synchronisation (which cannot be identified with the research client) and application installation file transfers via Bluetooth are also relatively well received among panelists, according to the questionnaire results. Most people are satisfied with the S60 native messaging client, the biggest avenues for improvements apparently being usability and speed of the client.

When projecting the daily usage patterns of person-to-person services (see the figure above), it is clear that voice is mostly used in daytime, whereas both SMS and MMS experience the highest peaks in the early evening. Both voice and SMS experience the most usage on Fridays, whereas MMS interestingly experiences the most usage on Sundays.

\section{DATA SERVICES}

On an aggregate level, roughly half of all observed packet data is already over WCDMA bearer (46 per cent). EDGE (21 per cent) and GPRS (18 per cent) are thus already behind WCDMA volumes in Finland, even when summing them together to form the $2 \mathrm{G}-2.5 \mathrm{G}$ data volume (39 per cent). No geographical focus was applied in recruitment. The most interesting observation is the share of WLAN traffic (15 per cent), although only a small share of panelists (1 per cent) have used the WLAN bearer. Among WLAN device owners, the share of WLAN traffic is even more (63 per cent). This is even though only 38 per cent of WLAN handset owners have actually generated packet data with WLAN (and 70

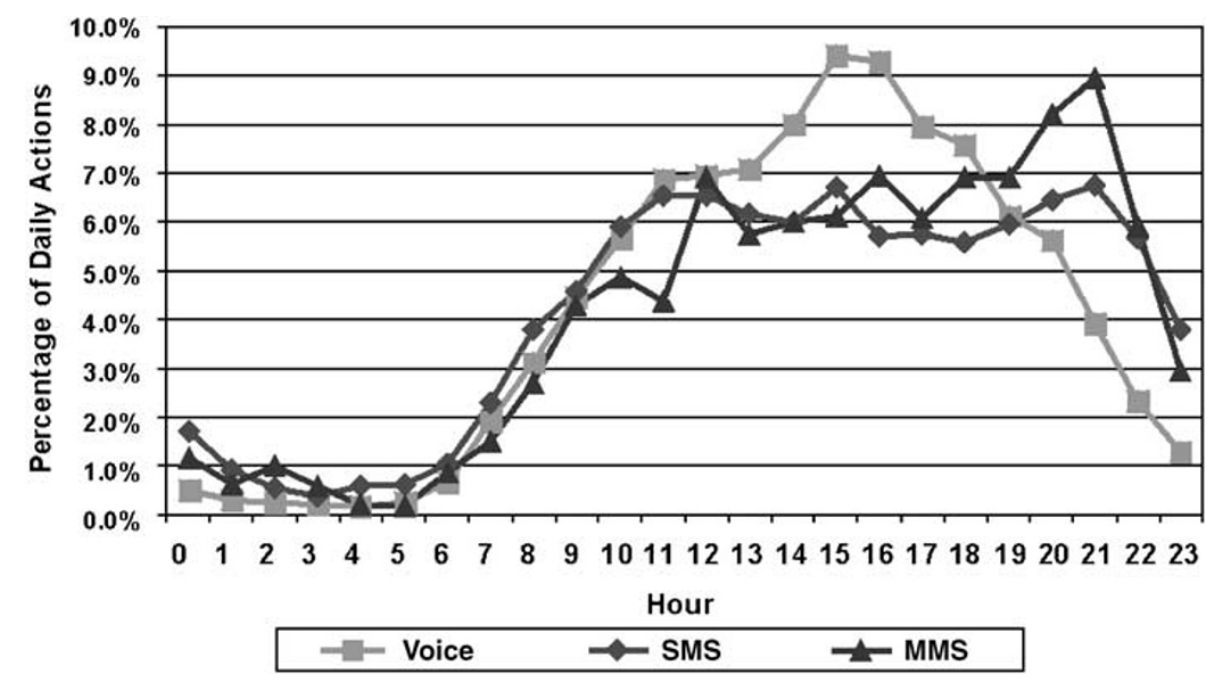

Figure 3: Distribution of communication actions 
per cent of WLAN device owners having generated any packet data in general). This indicates that the more capable the bearer, the easier it is to generate huge chunks of packet data. Faster bearers did not help earlier, as phones did not have rendering power to show websites quickly enough (browsing is still the key service in generating data). Now it is the opposite, the smartphone rendering is not a bottleneck that much any more, but instead the GPRS/EDGE bearers, which just cannot feed traffic quickly enough. WLAN bearers (and WCDMA) support fluent use of the internet. All in all, 84 per cent of all data traffic in the panel was of TCP/IP type, and 16 per cent was UDP or something else.

On an aggregate level, modem traffic represents quite a huge chunk of all data (about 43 per cent),although only a few users used the handset as a modem. Therefore, those who did use modem data generated data very intensively. This finding is along the lines of Kivi, ${ }^{16}$ in which it was observed that modem traffic is actually a major source of data traffic in mobile networks. Third-party application traffic represents 23 per cent of all traffic, which is quite a lot, taking into consideration that $\mathrm{S} 60$ native applications generated only 34 per cent of all data. This indicates that the mobile data service evolution is going towards the evolution of desktop and laptop PCs, in which people actively utilise a variety of data applications. In S60 native applications, it is the S60 native browser (75 per cent) that generates the most data, the S60 native messaging client (email, MMS) then representing about 21 per cent of all S60 native data. In thirdparty applications, browser applications have a tie-up with infotainment clients (operator clients, internet portals with dedicated applications) in packet data generation, both generating about 35-36 per cent of all third-party data. Also multimedia (streaming multimedia), utility (Anti-Virus, Putty, Search) and instant messaging third-party applications generate some traffic. When comparing GPRS/EDGE traffic to WCDMA, the major difference is that infotainment and multimedia applications acquire a higher share of all data traffic volume under
WCDMA. Indeed, these applications typically generate more data than messaging or browsing, if there is adequate bandwidth available. WLAN users mostly focused on browsing. When asked in the final questionnaire about the potential WLAN usage, browsing was the service most people were intending to use with smartphone WLAN. Email and file transfer were the next most important things, but, for example internet calls, streaming multimedia and instant messaging did not receive too much popularity among potential WLAN users.

Although browsing is still the driver data service, and about 70 per cent have generated browsing traffic at least once in the panel, only 23 per cent of panelists use it every month and 1 per cent every day. However, particularly subscribers with block-priced or flat-rate data plans are more likely to browse more actively than subscribers with no data plans at all (ie usage-based prices). A typical browsing session is $4 \mathrm{~min}$ long, and WLAN browsing sessions are on average (median: $7.6 \mathrm{~min}$ ) longer than cellular browsing sessions (median: $3.8 \mathrm{~min}$ ). Browsing data sessions are on average as long as multimedia or infotainment sessions, but instant messaging data sessions are roughly double the duration of browsing sessions, thus being quite long. The top 25 per cent of instant messaging sessions actually range from $20 \mathrm{~min}$ to even $50 \mathrm{~min}$ in length.

Out of browsing users, 80 per cent have visited operator sites and 25 per cent have visited Nokia's sites. On an aggregate level, 66 per cent of URL accesses go to the public domain already (non-operator sites), indicating that the mobile internet is getting closer to the fixed one. In other words, closed 'walled gardens' and operatorspecific WAP services do not have that big a role any more. An average duration at one domain is about $0.8 \mathrm{~min}$. In addition to Nokia and operator sites, the following domain brands attract people (in the order of penetration) in Finland:

- Google (18 per cent);

- Weatherproof (11 per cent);

- Yle (10 per cent);

- Iltasanomat (8 per cent); 
Table 3: Mean packet data traffic [MB/Month/User]

\begin{tabular}{lllrl}
\hline & $\begin{array}{l}\text { Usage- } \\
\text { based }\end{array}$ & $\begin{array}{l}\text { Block- } \\
\text { priced }\end{array}$ & Flat-rate & Total \\
\hline 2.5G Phone & 1.21 & 3.68 & 0.75 & 1.46 \\
3G Phone & 8.34 & 6.73 & 42.08 & 8.63 \\
Total & 5.64 & 6.39 & 39.02 & 6.72 \\
\hline
\end{tabular}

- MSpace (6 per cent);

- MTV3 (4 per cent);

- Eniro (4 per cent);

- Veikkaus (4 per cent).

Data plans have a significant effect on packet data generation. A typical subscriber with usage-based data plan generated only $307 \mathrm{~KB} /$ month, whereas a subscriber with a block-priced data plan generated $3,533 \mathrm{~KB} /$ month and flat-rate subscriber $2,954 \mathrm{~KB} /$ month. Data traffic amounts are also reported in arithmetic means in Table 3. When comparing the table below to similar tables related to voice and SMS usage, it can be noted that data service usage is probably more priceelastic than more mature service usage. More accurate studies indicate that in addition to data plan, the type of handset significantly affects usage. The impact of $3 \mathrm{G}$ capability among blockpriced data plan subscribers, for example, was an 86 per cent increase (in median usage intensity). Those customers who have a proper data plan (not usage-based) are more likely to explore data services. Modem usage has been explored by 8 , 22 and 52 per cent of usage-based, block-priced and flat-rate data users, respectively.

Five per cent of all panelists generate at least $20 \mathrm{MB}$ of packet data traffic/month. About 20 per cent of panelists generate at least $5 \mathrm{MB} /$ month. In cumulative terms, 10 per cent of panelists generate about 80 per cent of all packet data observed in the panel study, and 20 per cent of panelists generate about 90 per cent of all packet data observed. 8, 46 and 48 per cent of subscribers with usage-based, block-priced and flat-rate data plans generate at least $4 \mathrm{MB} /$ month of data traffic.

When asking about people's attitudes towards browsing, most respondents were simply looking for information (49 respondents) or readings news
(40 respondents). Also, webmail (38 respondents) was used by quite many. According to another question (asked with pop-up questions), at least 66 per cent of browsing sessions clearly related to free-time use. Seventy-four per cent of respondents said that they are satisfied with the smartphone browser, 13 per cent were very satisfied, 11 per cent were not satisfied and 2 per cent very unsatisfied. Most people said that speed, readability of display and ease of use are the major bottlenecks of smartphone browsers today. In particular, the speed/quality of connection and size/resolution of display were the two major challenges. A majority of respondents (92 per cent) said that browsing with a smartphone is different from browsing with a computer or a laptop. When carrying out research experiments with random browsing sessions in the panel, 25 per cent of browsing sessions resulted in some sort of failure according to users and panelists achieved their original objective in 75 per cent of browsing sessions. Hardly anybody said that data services work brilliantly, but similarly almost nobody said they work poorly. Most panelists said that data services almost work (133 respondents) or work as they should (141 respondents). Most people (68 per cent) considered their mobile internet connection expensive, whereas only 23 per cent said the price is reasonable.

\section{MULTIMEDIA USAGE}

Smartphones are nowadays called as multimedia computers $^{31}$ by Nokia. Indeed, multimedia is the next most popular service category after personto-person services. Thirty-three per cent of panelists have launched dedicated image editing/ viewing applications (not including Gallery). Thirty-seven and 53 per cent have launched dedicated movie and music players, respectively. Taking both dedicated movie and music players together, 64 per cent of panelists have used smartphones in playing back some sort of multimedia content in the offline mode. Thirteen per cent of panelists also generated packet data with music/video players, meaning some sort of streaming multimedia usage. It is evident in the data that those people who considered themselves 
as more experienced handset users have better adopted all multimedia applications. For example, 32 per cent of very experienced (their own opinion) panelists have tried streaming multimedia whereas only 10 per cent of beginner users have explored online multimedia. By aggregating over all multimedia applications in the panel, S60 native Gallery application represented 40 per cent of all launches as it is the main user interface to multimedia content in S60 devices. Imaging/ camera applications came second (37 per cent), followed my music playback (13 per cent). Movie players are still a niche smartphone service market.

Music playback is typically used when people wait for something and just want to kill time (18 respondents), followed by work (eight respondents) and sports context (six respondents). Offline multimedia playback experiences clear peaks in the morning 7-8am and afternoon 4-5pm, complemented by a slight peak at lunch break at $11 \mathrm{am}-12 \mathrm{pm}$. At least the former hours are typical commuting hours, suggesting that a typical use case for multimedia applications (music/movies) in smartphones is to use them in public transportation. When studied more accurately, these peaks were evident both in music player and radio, although in radio usage the peaks were clearer.

Thirty-four per cent of people say that they have not listened to music with smartphones, and 70 per cent say that they do not watch movies or videos with smartphones. When asked about the typical way of enjoying music content with smartphones, offline music track downloads/ copies (53 per cent) won against FM radio (34 per cent) and internet-downloaded music (4 per cent). Interestingly, in videos, people preferred streaming video (18 per cent), meaning that the recent push of mobile television services in packet data networks has had an impact on user behaviour. Just behind streaming video is offline video track downloads/copies (15 per cent). In music/video offline track downloads and copies, people first transfer the content to the smartphone with USB or Bluetooth and then play this content with the smartphone in the offline state (no active radio connections).
Eighteen per cent of all panelists have installed games during the panel, but about 55 per cent have played games during the panel. Beginner users are least likely to explore games, whereas more experienced users experience higher penetration numbers for games. Ten per cent of panelists have used dedicated blogging applications (supporting synchronisation/management of internet blogs), mostly Nokia's Lifeblog. Twentythree per cent have generated packet data with infotainment applications, which typically include major operator portals and the Finnish Kanavat client (tailored to access information/ entertainment content from the internet). Twentyseven per cent of panelists have used some radio applications during the panel.

Camera is one of the key features of smartphones. Ninety-four per cent have at least tried Camera (taken photos), and 57 per cent have recorded videos. About 30 per cent of panelists capture at least four photos/week. A typical panelist captures 2.3 photos/week. Teenage panelists are most active in capturing photos, particularly male teenagers. Male teenagers capture typically 20.1 photos/month, whereas, for example, 20-29-year-old men capture only 12.7 photos/month. Multimedia services in general are better adopted by younger panelists. Based on the questionnaires, panelists mostly prefer capturing people instead of things or landscapes with their smartphone camera, and most people are satisfied with the camera application. When asked about the potential avenues for development in smartphone cameras, quality of photos and speed of use were mentioned as things that should particularly be improved in camera. The ease of use was also considered as a feature with a potential for improvement. Smartphone camera usage peaks in the early evening both in photos and videos.

\section{CROSS-COUNTRY COMPARISONS}

Considerable handset-based research data exist (see also Verkasalo9): Finland (both 2005 and 2006), UK (both 2005 and 2006), France (2006), USA (2005) and Germany (both 2005 and 2006). For more accurate results, see Verkasalo. ${ }^{9}$ When evaluating averaged country data in 
communication (daily usage of SMS and voice, intensity of SMS and voice usage and extent of communication networks) and value-added service (penetration of browsing usage, intensity of packet data usage, weekly imaging usage penetration, application installation penetration, noncommunication application usage entropy) dimensions, it was found that the Finnish market ranks well in the communication service dimension. The UK and US markets lead in communication usage, but with continental Europe peers (Germany and France) Finland outperforms easily in communication. It was found that particularly bundled subscriptions have further driven communications usage in Finland. The most important single reason is that operators have bundled fixed plans (voice, SMS and data) to subscriptions, meaning that pricing is not usage-based any more. People see marginally zero prices and this clearly drives usage. Therefore, the Finnish person-to-person mobile service market has taken steps towards the UK and US markets.

In the value-added service dimension, the Finnish market does not perform that well, although bundling has positively contributed to data service usage through data plans. The UK and US markets still lead other markets, whereas in continental Europe and Finland the operator focus is still mostly on traditional mobile services. Also, cultural background, adopted usage behaviour, social norms and service availability/ performance do have a role to play. The key reasons why the VAS service usage index is still low for Finland (although data usage has significantly increased) is a slightly lower share of people browsing (although browsing users now actively generate data in Finland), A low share of people installing add-on applications and relatively simpler usage patterns in noncommunication application use (including, eg multimedia, utility, productivity applications).

In internet service usage (instant messaging, email), American subscribers are way ahead of Europeans. Fifty-two per cent of Americans (14-18 per cent of Finns) have used mobile email and 36 per cent (6-9 per cent of Finns) have used instant messaging. In MMS usage no significant differences exist. In video/movie player usage, Finns lag other markets, whereas in music player usage no differences exist. Although almost everybody in all countries has at least tried smartphone cameras, in weekly usage (share of people using cameras every single week) Finns are not active imaging users in comparison to consumers in other markets.

\section{LONGITUDINAL STUDIES}

When comparing Finnish data sets from 2005 and 2006, no significant differences exist in advanced mobile services. The major differences are in streaming packet data services (operators have pushed mobile television clients to the market), in which usage penetration has increased from 4 to 13 per cent. On the other hand, operator clients and other infotainment clients (Kanavat) have also experienced good adoption, penetration increasing from 5 to 35 per cent.

In packet data usage, the traffic amounts per user have increased quite a lot. In all data plan categories (usage-based pricing, block-pricing, flat-rate), the mean usage intensities have at least doubled. Whereas the mean traffic in 2005 was $3.1 \mathrm{MB} / \mathrm{month} /$ user and $6.4 \mathrm{MB} / \mathrm{month} /$ user in the block-priced category in 2006 , in the flat-rate category the increase was from $7.8 \mathrm{MB} /$ month/ user to $39 \mathrm{MB} / \mathrm{month} /$ user. The main drivers of packet data usage might include:

- promotion of data plans and pricing schemes;

- marketing of data services;

- better 3G coverage and capacity;

- more capable handsets;

- service availability/performance;

— increased interest towards data services among the subscriber domain.

In various comparisons that were done, it was always apparent that both the penetration and the intensity of usage in packet data services increase when moving from usage-based pricing schemes to block-pricing (reflecting the zero marginal cost of usage as the customer perceives it) and from 2.5G handsets to $3 \mathrm{G}$ handsets (reflecting both handset capability and the possibility to deploy enhanced radio access technologies) (Figure 4). 

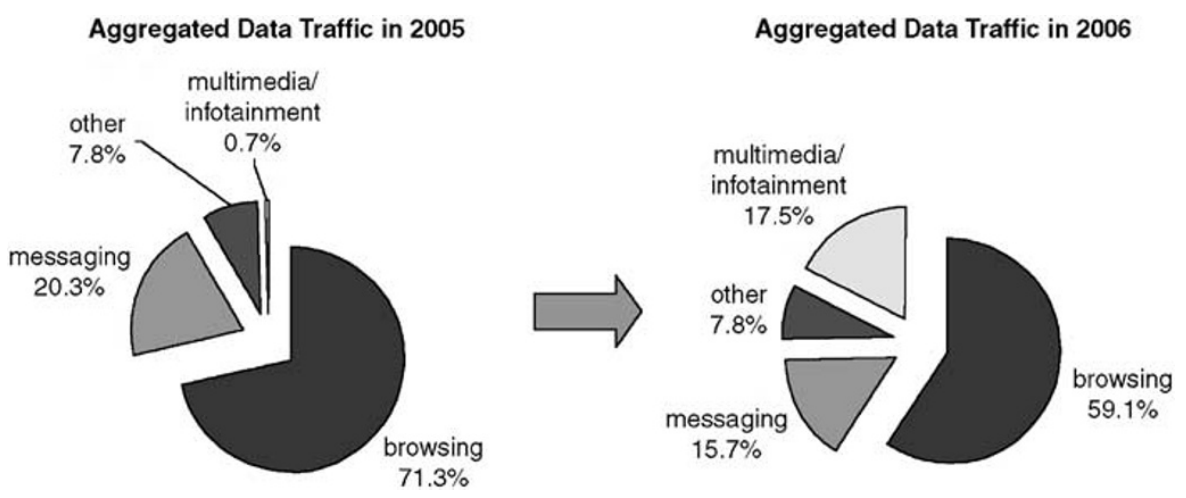

Figure 4: Mobile data service trends

In terms of data service evolution, the share of multimedia/infotainment traffic has increased from 0.7 per cent (in 2005) to 17.5 per cent (in 2006), and the share of messaging traffic has declined from 20.3 per cent (in 2005) to 15.7 per cent (in 2006). The above figure projects the mobile data usage trends. The mobile internet usage is getting closer to the fixed domain as people move from simpler data services to more advanced ones. Interestingly, in browsing usage, the share of public internet domain accesses has remained almost the same at 64-66 per cent as in 2005. Although people are more active in exploring public internet content, the bundled subscriptions with preloaded operator bookmarks have a counter effect on the emergence of the mobile public internet outside of 'walled gardens'.

\section{ADOPTION RESEARCH}

Subscriber opinions were asked about their motivation to use some emerging mobile services. These opinions were then compared to actual usage observed with the research client.

The results are as expected. People with higher motivation to use services also actually in many cases use the services with a higher probability. For example, 84 per cent out of those who were strongly intending to use mobile WEB/WAP browsing actually did so. On the other hand, 18 per cent of those who were strongly against exploring mobile browsing did browse. The share of people browsing monotonically increased in motivation to use (Figure 5).
By measuring the share of highly motivated panelists who then actually did not use the service, it is possible to identify bottlenecks in service usage. If the motivation is high, but no usage is observed, there have to be some technical problems, pricing must be expensive or service performance/availability poor. Sometimes, service configuration is simply too difficult. For browsing, the success rate of highly motivated customers was 84 per cent. Similar rates for mobile email, instant messaging, MMS, games, streaming multimedia and normal (offline) multimedia players are $60,44,82,88,33$ and 78 per cent. Therefore, particularly email, instant messaging and streaming multimedia services still have major bottlenecks that prevented motivated users from using them. These services typically require expertise on configuring or installing applications.

\section{END-USER SEGMENTATION}

Usage-based mobile service data accurately reflect the behavioural patterns that different users have in smartphone usage. To provide an exemplary approach for a new kind of end-user segmentation approach, the data acquired through handset-based logs are clustered here with SPSS TwoStep cluster analysis (automatic determination of the number of clusters based on usage data, standardised variables, Schwartz's Bayesian clustering criterion, log-likelihood distance measures). In smartphone services, at least three kinds of different services can be identified: communication, data and multimedia. The goal of the segmentation exercise here is to find unique 


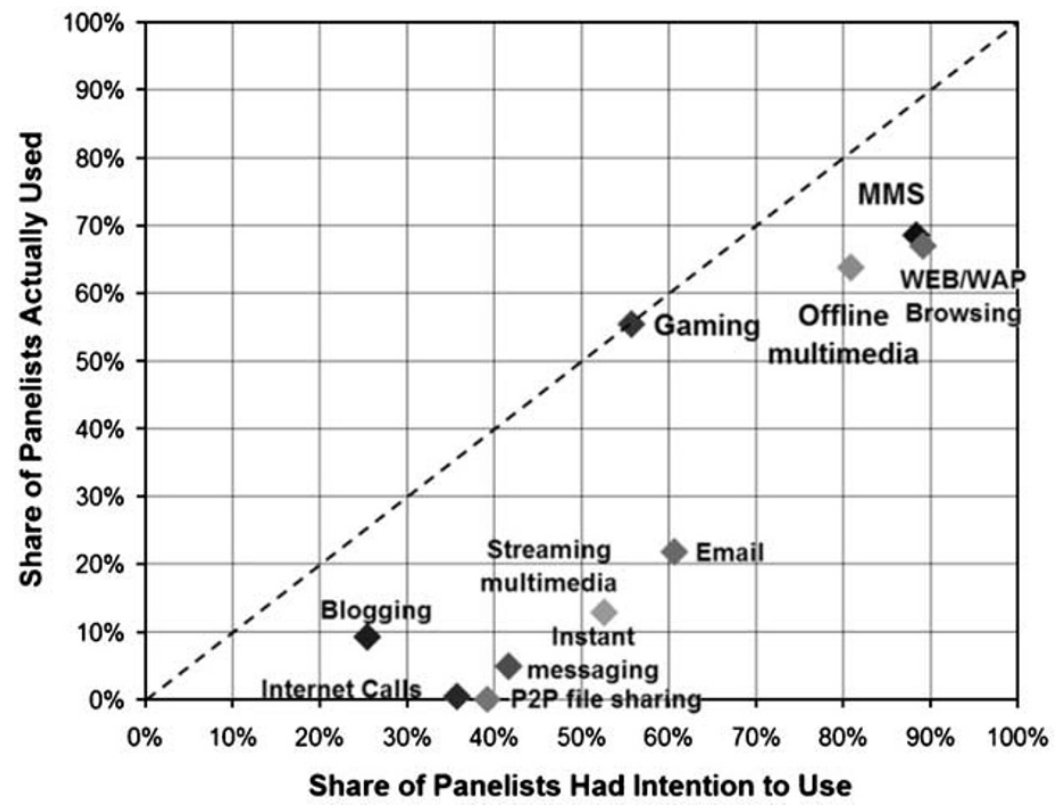

Figure 5: Adoption of mobile services

user segments of users based on their actual usage patterns in these three service categories.

Measurement of usage intensity in these service categories should be based on the specific characteristics of the services included. In the clustering approach, voice calls are measured as the number of outbound voice calls per day, multimedia usage is measured in minutes of multimedia usage (eg imaging, music playback) per day and data usage is measured in megabytes of data traffic generated per day. By inputting these three variables into the hierarchical clustering approach, three different user segments were identified. Based on subjective analysis of the differences in these segments, the segments are named here as 'normal users', 'active users' and 'high-tech users'. The segments differ particularly in their locus of usage with regard to the above-mentioned three service categories.

Detailed SPSS output listings of the clustering analysis are presented in Appendix A. Normal users represent about 60 per cent of panelists, active users 36 per cent and high-tech users 4 per cent. Normal users are pretty passive in almost all mobile service categories, and they typically have only $25 \mathrm{~min}$ of smartphone usage per day. Active users, on the other hand, possess much more active communication usage patterns than normal users or high-tech users, having about $29 \mathrm{~min}$ of communication usage per day and $49 \mathrm{~min}$ of total smartphone usage. Active users have the most active voice and SMS usage activities. High-tech users have active multimedia and data service usage patterns, but they represent a small share of panelists. Although they have the highest number of smartphone usage minutes (mainly because of very active data and multimedia service usage that drives non-communication usage), they have lower ABPU (average billing per user in euros/ month) than active users, who have the main locus of usage in communication. The generated user segments provide an example of a usage-data based end-user segmentation that could be utilised in new empirical mobile end-user segmentation models, sociological studies or adaptive mobile software.

\section{QUESTIONNAIRE RESULTS}

Various questions were asked from the panelists in three different kinds of questionnaires: Beginning questionnaire (before the study period), Mobile questionnaire (pop-up questions during the panel study) and Final questionnaire (when the study period ends). The base for the beginning 
questionnaire was 984 respondents, 380 respondents for mobile questionnaire and 548 respondents for the final questionnaire.

Most respondents (65 per cent) think they would not have less friends did they not have a cell phone. This indicates that for most panelists, there would be an active social life even without cell phones. Most panelists (67 per cent) agree, however, that they would feel lost without their smartphones. Only a small share of panelists (36 per cent) thought that personalising the smartphone (with eg wallpapers or ring tones) is important, which is slightly surprising. In a similar vein, only 31 per cent of panelists said they would feel embarrassed with old-fashioned handsets. Typically, people change for a new handset model every 1-2 years (47 per cent). Nobody said that they would change for a new handset model at least every six months. Only 20 per cent of panelists claim that they are among the first people to purchase new handset models when they come to the market. This indicates that the Finnish sample of subscribers is not that early-adopter-biased after all.

Many pricing-related questions were asked. In general, people mostly criticise the price of MMS messages (148 respondents said that the price of MMS negatively affects usage) and mobile internet (158 respondents). The next most criticised services were email (91 respondents) and application installations (89 respondents). Sixty-five respondents said that voice calls are too expensive. People did not have problems with the pricing of instant messaging and SMS. Forty-two per cent of panelists said pricing is the most critical issue limiting the use of high-end new services currently. Thirty-one per cent of panelists instead said that technical implementation is the most important challenge. The rest of the answers were divided into misunderstanding the customer (7 per cent), poor marketing (13 per cent) and suboptimal market situation (1 per cent).

In terms of technical performance and ease of use (configuration), people emphasised particularly email (143 respondents said that technical issues negatively affect the use of mobile email) and mobile internet (169). The next most difficult/ poorly performing services were MMS (55), instant messaging (63) and application installations (47). Voice and SMS did not experience too many challenges in the technical domain.

Pricing is definitely important among panelists. Forty-four per cent of panelists said that they actively follow prices and change their behaviour accordingly. Out of those who properly answered the question of mobile e-commerce, 70 per cent have used smartphones in purchasing electronic content (wallpapers, ringing tones) and 42 per cent have used smartphones in purchasing goods or using some services (eg mobile banking, SMS parking tickets).

\section{DISCUSSION OF THE RESULTS}

In general, only some of the results can be compared to earlier results. For example, FICORA $^{32}$ has published numbers only on mobile voice calling in Finland. In FICORA's research, they ended up with an average of about $400 \mathrm{~min}$ of voice call usage/subscriber/month, whereas in this study the total monthly number of voice minutes was estimated at 384 , thus being pretty close. In data service usage, few comparative references can be found. Antero $\mathrm{Kivi}^{33}$ studied the whole mobile data market in Finland with network-based measurements, and found the share of modem generated traffic to be huge (more than 70 per cent). In the findings of this paper, the share of modem traffic was not that high (less than half), but this probably results from the fact that the research objects in this study are early-adopters with well-equipped handsets and bundled smartphone software. In general, the share of multimedia and mobile browser data volume is higher in this sample of early adopters than in Kivi's market-level studies. ${ }^{16,33}$

Some earlier references to papers using the same handset-based research method in Finland can be found (see eg Hämmäinen et al. ${ }^{23}$ and Verkasalo $^{9}$ ). The findings of this paper confirm that Finnish early-adopter users are indeed moving to multimedia services both time and data volume wise. In addition, general smartphone usage activity has increased. The observations are not surprising in this regard, as the assumption is that the mobile services market grows and 
usage-level observations should confirm increasing data usage and complexity in general mobile service consumption patterns.

In many instances, the kinds of results reported in this report have not been published earlier. The results combining questionnaires (eg user motivations) and accurate usage-level data in this scale are pioneering in the academic world. In a similar fashion, handset-based research results related to the consumption of time, offline usage and usage-based segmentation are novel. The results of this paper not only confirm that changes in end-user mobile service consumption patterns have taken place in Finland in one year, but they additionally suggest that the handsetbased research platform can functionally extend the tools available for mobile end-user research by combining many kinds of usage data together and also mixing in questionnaire-based data in appropriate study contexts.

\section{CONCLUSION}

A new handset-based mobile end-user research platform provides a holistic approach in studying smartphone service usage in coordinated panels. This paper provided an empirical look at the Finnish mobile early-adopter market, thereby demonstrating the capabilities that the new platform possesses. Most of the analysis was performed with programmable (and therefore scalable) data analysis tools specifically tailored for this project only.

People in Finland spend increasing amounts of time with smartphones, and particularly emerging smartphone services such as browsing and multimedia capture higher shares of the user's time than earlier. The mobile internet is gradually emerging, but technical problems still remain as bottlenecks for wider adoption of these services. It is observed, however, that new pricing plans have a significant effect on the usage of all voice, SMS and data services. Therefore, prices are not irrelevant. New end-user segmentation models can be deployed, with the new research platform providing data based on actual end-user behaviour.

Future handset-based studies should focus on emerging mobile services and interesting new phenomena, such as the emergence of the mobile internet, contextual usage patterns and alternative radio access technologies. Under many circumstances, as identified in this empirical report, the new handset-based mobile service research platform has many advantages in comparison to alternative ways of performing mobile end-user research.

\section{References}

1 Kotler, P. and Armstrong, G. (1996) 'Principles of Marketing', Pearson Education, Inc., Upper Saddle River, New Jersey.

2 Ojala, T., Korhonen, J., Aittola, M., Ollila, M., Koivumäki, T., Tähtinen, J. and Karjaluoto, H. (2003) 'SmartRotuaari Context-aware mobile multimedia services', Proceedings of the 2nd International Conference on Mobile and Ubiquitous Multimedia, Norrköping, Sweden, 2003.

3 Abowd, G. D., Atkeson, C. G., Hong, J., Long, S., Kooper, R. and Pinkerton, M. (1997) 'Cyberguide: A mobile context-aware tour guide', ACM Wireless Networks, Vol. 5, pp. 421-433.

4 Christensen, C. M. (1997) 'The Innovator's Dilemma', Harvard Business School Press, Boston.

5 Iimi, A. (2005) 'Estimating demand for cellular phone services in Japan', Telecommunications Policy, Vol. 29, pp. 3-23.

6 Maslow, A. H. (1943) 'A theory of human motivation', Psychological Review, Vol. 50, pp. 370-396.

7 Heinonen, K. and Pura, M. (2006) 'Classifying mobile services', Presented at Helsinki Mobility Roundtable, 1st-2nd June, 2006, Helsinki.

8 Clarke, I. and Flaherty, T. (2003) 'Mobile portals: The development of M-commerce gateways', in Mennecke, B. E., Strader, T. J. (eds), 'Book Mobile Commerce: Technology, Theory, and Applications', Idea Group Publishing, Hershey, pp. 185-201.

9 Verkasalo, H. (2007) 'A cross-country comparison of mobile service and handset usage', Licentiate's thesis, Helsinki University of Technology, Networking Laboratory, Finland.

10 Rogers, E. M. (1962) 'Diffusion of Innovation', The Free Press, New York.

11 Moore, G. (1991) 'Crossing the Chasm', Harper Business, New York, NY

12 Fink, A. (1995) 'The Survey Handbook', Sage Publications, London.

13 Martin, E. (1983) 'Surveys as social indicators: Problems in monitoring trends', in Rossi, P., Wright, J., Anderson, A. (eds), 'Handbook of Survey Research', Academic Press, San Diego, CA, pp. 677-743.

14 Peuhkuri, M. (2002) 'Internet traffic measurements - Aims, methodology, and discoveries', Licentiate's thesis, Networking Laboratory, Helsinki University of Technology.

15 Viipuri, T. (2005) 'Traffic analysis and modeling of IP core networks', Master's Thesis, Helsinki University of Technology.

16 Kivi, A. (2006) 'Mobile internet usage measurements: Case Finland', Master's Thesis Series, Networking Laboratory, Department of Electrical and Telecommunications Engineering, Helsinki University of Technology, Espoo, Finland, May 2006. 
17 Kamvar, M. and Baluja, S. (2006) 'A large scale study of wireless search behavior: Google', CHI 2006, 22nd-27th April, 2006, Montréal, Québec, Canada.

18 Opera (2006) Opera Software ASA press release 8th August, 2006. Mobile Browsing Bonanza: One billion Web pages viewed with Opera Mini.

19 Wei, C. -P. and Chiu, I. -T. (2002) 'Turning telecommunications call details to churn prediction: A data mining approach', Expert Systems with Applications, Vol. 23 (August), pp. 103-112.

20 Verkasalo, H. and Hämmäinen, H. (2007) 'A handset-based platform for measuring mobile service usage', INFO: The Journal of Policy, Regulation and Strategy, Vol. 9, No. 1, pp. 80-96.

21 Verkasalo, H. (2005) 'Handset-based monitoring of mobile customer behavior', Master's Thesis, Networking Laboratory, Helsinki University of Technology.

22 Verkasalo, H. and Hämmäinen, H. (2006) 'Handset-based monitoring of mobile subscribers', Presented at Mobility Roundtable, 1st-2nd June, 2006, Helsinki, Finland.

23 Hämmäinen, H., Verkasalo, H. and Kivi, A. (2006) 'The real usage patterns of mobile subscribers: Regulatory implications in Finland', Presented at ITS Conference, 12th-16th June, 2006, Beijing, China.

24 Verkasalo, H. (2006a) 'Mobile data service evolution Empirical observations on packet data service adoption', Presented at CICT Conference 2006 - 3rd International CICT Conference, The Center for Information and
Communication Technologies, Technical University of Denmark, 30th November-1st December, 2006.

25 Verkasalo, H. (2006b) 'Empirical observations on the emergence of mobile multimedia services in the U.S. and Europe', Presented at MUM 2006 - The 5th International Conference on Mobile and Ubiquitous Multimedia. Stanford University, California, 4th-6th December, 2006.

26 http://www.chetansharma.com/Worldwide Wireless Data Trends.doc.

27 Kivi, A. (2007b) 'Measuring mobile user behavior and service usage: Methods, measurements points, and future outlook', Proceedings of the 6th Global Mobility Roundtable, 1st-2nd June, 2007, Los Angeles, California, USA, 2007.

28 http://www.swbusiness.fi/portal/34/?id=243.

29 http://www.kaupunginosat.net/oulunkyla/arkistot/2004/ elisatupla.htm.

30 http://www.speedscript.biz/?p=speed.

31 http://www.vnunet.com/vnunet/news/2145367/nokiaabandons-making-mobile.

32 FICORA (2006) 'Markkinakatsaus 2/2006 (in Finnish)', Seasonal publications, Finnish Communications Regulatory Authority, Helsinki.

33 Kivi, A. (2007a) Mobile Data Service Usage Measurements Results 2005-2006, 2007, COIN project report, Helsinki University of Technology.

\section{APPENDIX A}

\section{SPSS Output of the Clustering Approach}

\section{TwoStep Cluster}

Cluster distribution

\begin{tabular}{lrrr}
\hline & N & \% of Combined & of Total \\
\hline Cluster & & & 60.1 \\
$\quad$ Normal users & 396 & 36.1 & 57.0 \\
Active users & 238 & 3.8 & 34.2 \\
High-tech users & 25 & 100.0 & 3.6 \\
Combined & 659 & & 94.8 \\
Excluded cases & 36 & & 5.2 \\
Total & 695 & & 100.0 \\
\hline
\end{tabular}

\section{Cluster Profiles}

Centroids

\begin{tabular}{|c|c|c|c|c|c|c|}
\hline & \multicolumn{2}{|l|}{ Traffic week } & \multicolumn{2}{|c|}{ Voice calls out day } & \multicolumn{2}{|c|}{ Multimedia minutes day } \\
\hline & Mean & Std. Deviation & Mean & Std. Deviation & Mean & Std. Deviation \\
\hline \multicolumn{7}{|l|}{ Cluster } \\
\hline Normal users & 940.4183 & $2,648.43829$ & 1.1857 & 0.58437 & 2.7063 & 2.85670 \\
\hline Active users & 993.1433 & $2,022.35074$ & 3.5192 & 1.43772 & 6.8583 & 5.59047 \\
\hline $\begin{array}{l}\text { High-tech } \\
\text { users }\end{array}$ & $2,0977.35$ & $57,799.44205$ & 2.1997 & 1.76267 & 39.6436 & 22.34085 \\
\hline Combined & $1,719.5864$ & $11,924.03022$ & 2.0670 & 1.51451 & 5.6071 & 9.16549 \\
\hline
\end{tabular}




\section{Means}

\begin{tabular}{|c|c|c|c|c|}
\hline \multicolumn{5}{|l|}{ Median } \\
\hline & \multicolumn{4}{|c|}{ TwoStep cluster number } \\
\hline & 'Normal users' & 'Active users' & 'High-tech users' & Total \\
\hline voice_calling_minutes_day & 7.0423 & 16.0667 & 8.9718 & 9.3240 \\
\hline voice_calls_out_day & 1.1908 & 3.2230 & 1.7857 & 1.7237 \\
\hline Com_minutes_day & 14.0212 & 29.8086 & 19.2014 & 19.3506 \\
\hline Noncom_minutes_day & 8.2606 & 16.4814 & 53.3843 & 12.0052 \\
\hline total_smartphone_minutes_day & 24.6520 & 49.0918 & 68.6601 & 34.4045 \\
\hline messages_sms_sent_day & 0.7692 & 1.6984 & 1.4328 & 1.0670 \\
\hline traffic_week & 136.3318 & 211.0877 & 622.2210 & 170.3105 \\
\hline messages_mms_sent_day & 0.0357 & 0.0469 & 0.0448 & 0.0435 \\
\hline photos_week & 1.9091 & 3.6207 & 3.9846 & 2.3333 \\
\hline multimedia_minutes_day & 1.6217 & 5.5845 & 32.0573 & 2.8646 \\
\hline ABPU & 30.00 & 50.00 & 42.50 & 40.00 \\
\hline
\end{tabular}


Handset-based measurement of smartphone service evolution in Finland 宋

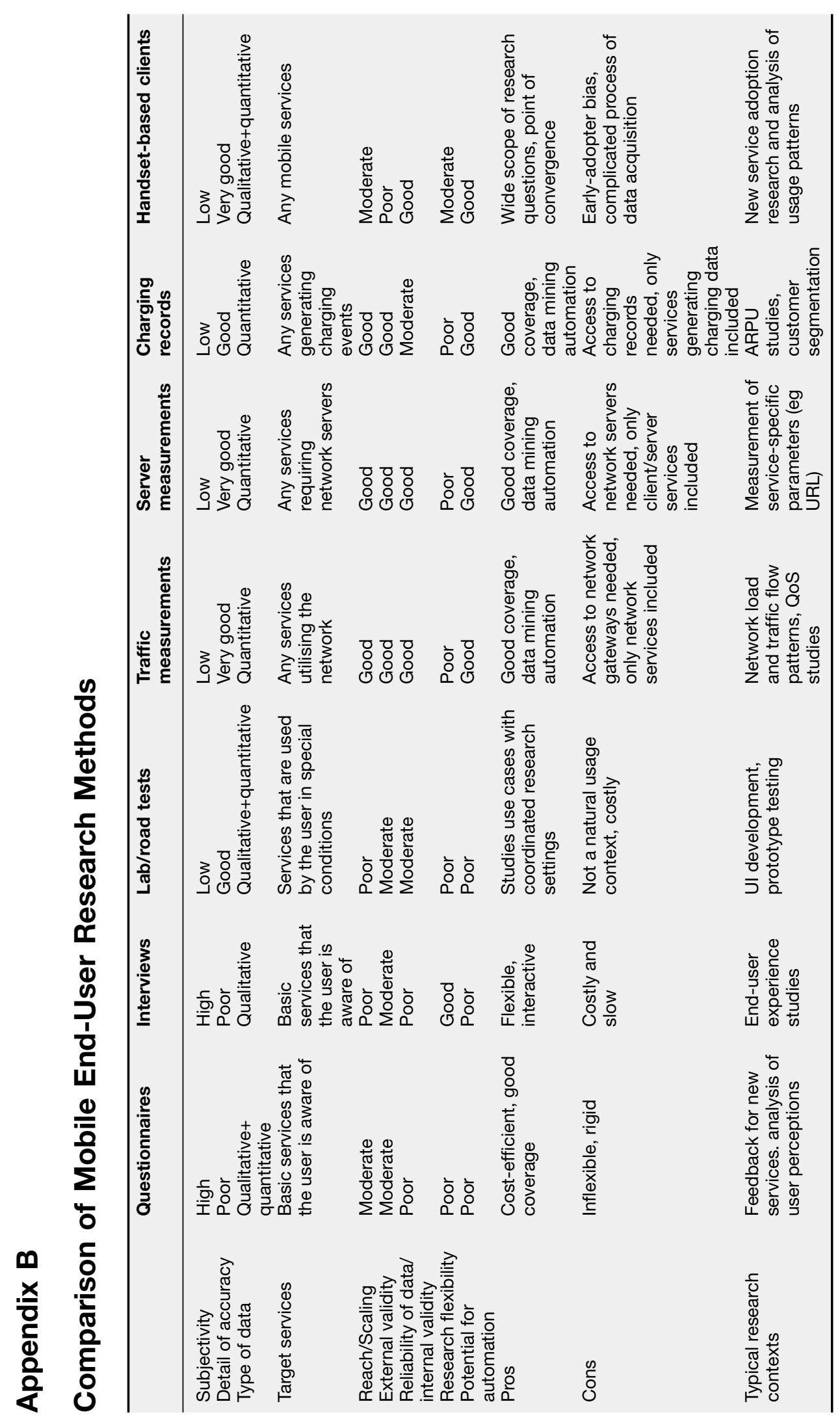

